\title{
WILLIAM ROBERTS, Saint-Amant, Holland House, and the Queen of England
}

\section{Chiara Rolla}

\section{(2) OpenEdition}

\section{Journals}

\section{Edizione digitale}

URL: http://journals.openedition.org/studifrancesi/33091

DOI: 10.4000/studifrancesi.33091

ISSN: 2421-5856

\section{Editore}

Rosenberg \& Sellier

\section{Edizione cartacea}

Data di pubblicazione: 1 décembre 2005

Paginazione: 633

ISSN: 0039-2944

\section{Notizia bibliografica digitale}

Chiara Rolla, «WILliam roberts, Saint-Amant, Holland House, and the Queen of England», Studi Francesi [Online], 147 (XLX | III) | 2005, online dal 01 novembre 2015, consultato il 18 avril 2021. URL: http:// journals.openedition.org/studifrancesi/33091 ; DOI: https://doi.org/10.4000/studifrancesi.33091

Questo documento è stato generato automaticamente il 18 avril 2021.

\section{cc) $(1) \odot$}

Studi Francesi è distribuita con Licenza Creative Commons Attribuzione - Non commerciale - Non opere derivate 4.0 Internazionale. 


\title{
WILLIAM ROBERTS, Saint-Amant, Holland House, and the Queen of England
}

\author{
Chiara Rolla
}

\section{NOTIZIA}

WILLIAM ROBERTS, Saint-Amant, Holland House, and the Queen of England; "Analecta Husserliana", LXXXI, A.-T. Tymieniecka éd., 2004, pp. 45-60.

1 L'articolo, che contiene anche la traduzione in inglese dell'ode A leurs Serenissimes Majestez de la Grand'Bretagne, ripercorre i momenti più importanti che hanno caratterizzato l'ispirazione e la creazione di quel componimento.

2 Nel settembre del 1631 Saint-Amant fece un viaggio in Inghilterra ed ebbe l'occasione di incontrare re Carlo I ed Henrietta, sua consorte nonché figlia di Enrico IV di Francia, in soggiorno a Holland House. Il poeta rimase profondamente colpito da questa residenza, tanto da disseminare il poema di riferimenti precisi al luogo e al paesaggio circostante. L'A. sottolinea inoltre come il componimento si caratterizzi quale un vero e proprio poema-spettacolo, i cui protagonisti sono i sovrani. Saint-Amant mette in scena un balletto ambientato nello splendido parco che circonda la residenza, descritto per l'occasione, come una sorta di scenario da fiaba. 